\title{
Cesarean Section and Delivery Litter Results Domain
}

National Cancer Institute

\section{Source}

National Cancer Institute. Cesarean Section and Delivery Litter Results Domain. NCI

Thesaurus. Code C95093.

A subject domain utilized for the submission of information encompassing and representing data, vocabulary or records related to cesarean section and other methods of delivery of animal litters. 